\title{
APPLYING THE SUPPLY CHAIN OPERATIONS REFERENCE (SCOR) MODEL FOR THE EVALUATION OF SEVERAL URBAN CONSOLIDATION CENTRE OPERATING MODELS
}

\author{
Janjevic, $\mathrm{M}^{1}$ Nsamzinshuti, $\mathrm{A}^{1} ;$ Rigo, $\mathrm{N}^{1}$ and Ndiaye $\mathrm{AB}^{1}$ \\ ${ }^{I}$ Qalinca Labs, Brussels School of Engineering Université Libre de Bruxelles, Brussels, Belgium
}

\begin{abstract}
Urban Consolidation Centres (UCCs) are a popular measure in city logistics, but many of the UCC projects are granted only a short life. These facilities are often view as creating benefits for the society and costs for the private sector. Recent research and experiences show however that additional value-added activities performed in these platforms are able to increase the attractiveness of these city logistics schemes. This paper proposes the application of the Supply Chain Operations Reference (SCOR) model in order to assess the impact of the UCCs on the overall supply chain performance. Authors first perform a review of current evaluation techniques for the UCC projects and highlight the relevance of a supply chain focused approach. They present the Supply Chain Operations Reference (SCOR) model and discuss its relevance for the evaluation of UCC projects. They then analyse 10 recent UCC case studies which leads to highlighting the existence of three distinct operating models. Finally, they apply the SCOR model to the different UCC operating models. The study confirms the UCCs on the reliability, responsiveness and agility of the supply chains. This brings an innovative aspect to the UCC projects evaluation which traditionally only focuses on cost, environmental or asset utilisation related metrics.
\end{abstract}

Keywords: Urban Freight Transport; City Logistics; Urban Consolidation Centres; Evaluation; Supply Chain Operations Reference Model; SCOR

\section{Introduction}

Urban consolidation centres (UCCs) are a popular measure in city logistics (Verlinde et al., 2012; Ville et al., 2012). They have been subject to many trial projects and implementation cases. Allen et al. (2012) identifies 114 UCC schemes in 17 countries that have been the subject of either a feasibility study, trial or a fully operational scheme in the last 40 years. However, many of the UCC projects are granted only a short life (Verlinde, 2015). (Lebeau et al., 2015a) demonstrate that a large majority of the UCCs that were operating in the previous decades have failed. In a European review of 75 UCC initiatives, Morana et al. (2014) find that only 30 (or around 40\%) of the considered schemes are still operational. This figure is however to take with caution since it accounts for UCCs whose start dates extend through a long time period.
UCC schemes are traditionally seen as creating benefits for the society, but creating an additional cost for the private sector. On one hand, Verlinde (2015) performs a systematic review of 93 unique UCCs impact assessments and find a positive on the urban freight vehicle kilometres (79\% of the ex-ante assessments and $100 \%$ of the ex-post assessments observed a decrease), confirming their potential to decrease the environmental impact of the urban freight transport. On the other hand, there is a general consensus that the transhipment operations introduce an additional cost in the transport chain (e.g. Allen et al., 2012; Browne et al., 2005; Marcucci and Danielis, 2008; Verlinde et al., 2012) and the failure of the UCC schemes in the past has therefore resulted in significant concerns with regards to their financial viability (Quak and Tavasszy, 2011). This specific 
vision on the UCC projects results in the necessity of introducing public subsidies that aim in offsetting additional costs for the private sector while maintaining the societal benefits. Browne et al. (2005) find that there is no strong evidence that any truly self-financing schemes and indicates that the success of the UCCs is dependant on the availability of public funding whereas Van Duin (2009) mentions the existence of subsidies as one of the major success factors for UCC operations.

Most of the existing evaluation techniques used for assessing the UCC projects reflect this specific vision. Browne et al. (2005) summarize the metrics that are typically used in UCC evaluations. We can put these in two following categories: measures affecting the environmental impact of urban freight transport (changes in the number of vehicle trips, changes in the number of vehicle kilometres, changes in the number of vehicles, changes in parking time and frequency, changes in total fuel consumed, changes in vehicle emissions) and measures effecting the efficiency of the last mile operations (changes in travel time, goods delivered per delivery point, vehicle load factor, changes in operating costs).

Recent research contributions and recent UCC experiences show that UCC projects can bring benefits that go beyond the environmental impact. UCCs can create value further in the supply chain and improve the overall supply chain performance. This is particularly relevant for some novel UCCs operating models. In fact, the purpose and design of the UCCs schemes has evolved over time (Allen et al., 2012). In the 70's, UCCs were seen as simple transhipment points (Allen et al., 2012) - however, transhipment operations do not add any value to the cargo and generally create an additional cost, resulting in a negative economic impact. However, recent UCCs experiences offer a range of additional value-added services that go beyond the consolidation and crossdocking (Panero et al., 2011; Triantafyllou et al., 2014; Allen et al., 2012) and that can increase the attractiveness of these logistical platforms. For example, Allen et al. (2012) and Björklund and Abrahamsson (2015) find that the implementation of an UCC can result in value added retail and logistics activities for the receiver and enhance the supply chain efficiency.
In order to account for this effect, several authors (e.g. Browne et al., 2005; Marinov et al., 2008) highlight the importance of assessing the costs and benefits of these initiatives in a wider context and analysing the integration of these initiatives into the larger supply chains.

In this framework, this paper aims in analysing the potential impacts of the UCC schemes on the overall supply chain performance. Authors first perform a review of current evaluation techniques for the UCC projects and highlight the relevance of a supply chain focused approach. They present the Supply Chain Operations Reference (SCOR) model and discuss its relevance for the evaluation of UCC projects. They then analyse 10 recent UCC case studies in order to highlight the existence of three distinct operating models. Finally, they apply the SCOR model to the different UCC operating models and conclude with regards their impact on the overall chain performance.

\section{Using SCOR model for UCC projects evaluation}

\section{Current evaluation techniques for the UCC projects}

Evaluating the city logistics initiatives is a crucial task for the scientific community (Danielis et al., 2015). The evaluation of city logistics schemes involves consideration of a wide range of benefits and costs for both the public and private sectors (Thompson, 2014). It also brings some specific challenges such as the diversity of the stakeholders and objectives, the difficulty of assessing the costs and benefits, the lack of definition the problem owner, the lack of data or the diversity of context (Balm et al., 2014). The variety of approaches for the evaluation of city logistics initiatives documented in the literature reflects this complexity.

City logistics initiatives evaluation techniques can vary according to a number of factors. They can be ex or post evaluations. They can be categorized as either single (monetary) criterion or multi-criterion (nonmonetary) (Thompson, 2014). Evaluation techniques also vary according to the scope of evaluation which is related to the definition of the system boundaries that need to be defined for designing surveys and models (Thompson, 2014). Danielis et al. (2015) summarize three approaches in the performance 
evaluation techniques for the city logistics with regards to the evaluation scope: (1) evaluations at firm level, (2) the firm within a supply chain and (3) the supply chain in a city context. In the specific case of UCC evaluations, Browne et al. (2005) highlight that the boundaries of the evaluation process should ideally be as far-ranging as possible, but observe that previous analyses of the impacts of UCCs have tended to focus only on the very specific changes in goods movements, while ignoring any wider changes. Finally, evaluation techniques can also vary according to the number of stakeholders included in the analysis. We will now summarize some common evaluation approached to the assessment of the UCCs in the literature.

Some articles focus on the firm level and discuss specifically the financial viability of the UCCs. In this category, Janjevic and Ndiaye (2016) investigate the financial viability of the UCCs by specifying the potential revenues and costs linked to its operation and Tsamboulas and Kapros (2003) develop a model for the financial evaluation of investments for a Freight village with public and private financing.

A common approach consists in evaluating the UCCs based on the logistical indicators (e.g. UCC throughput), the economic indicators (e.g. financial results of the UCC solution) and the environmental effects (e.g. reduction in the vehicle-km or reduction of the emissions). For example, ADEME (2004) performs an evaluation of the UCCs in La Rochelle and in Monaco and presents the operational, the financial and the environmental results. Morana and Gonzalez-Feliu (2010) provide an assessment of a UCC Cityporto in Padova (I) by discussing its profitability as well as the environmental and social effects. Van Rooijen and Quak (2010) examine the impacts of the Binnenstadservice UCC on the city of Nijmegen (NL) after one year of operation by focusing on logistical effects (e.g. number of truckkilometres in city centre, total truck travel time) and the resulting effects on air quality, noise and hindrance. Browne et al. (2011) evaluate the use of an urban micro-consolidation centre in central London (UK) by explicating the environmental effects (distance travelled and greenhouse gas emissions, daytime road occupancy, kerbside occupancy while unloading) and the economic effects (impact of the trial distribution system on operating costs). LaMilo
(2015) provides a comprehensive business case of a Camden Consolidation centre (UK) by detailing the commercial, operational, financial and environmental aspects.

In some cases, the effects of the UCC on the users (e.g. level of service or cost reduction) are included in this analysis. For example, Van Duin et al. (2008) performs a cost-benefit analysis in order to assess the effects of the introduction of the UCC on the city distribution centre (i.e. its profitability), on the public affairs (i.e. the societal value) and on the commercial stakeholders (i.e. costs and benefits for UCC users). van Duin et al. (2010) study the feasibility of a UCC in Hague (NL) and provides costs and benefits of several scenarios by focusing on three main elements: vehicle kilometre reduction, the net benefits of the UCC and the service level for the stakeholders. Quak and Tavasszy (2011) follow-up on the analysis by Van Rooijen and Quak (2010) for the Binnenstadservice UCC on the city of Nijmegen (NL) and detail elements relevant to the impacts on the users, such as savings by the carriers. Leonardi et al. (2015) performs an ex-ante assessment of a network of UCCs in Luxembourg, by estimating economic effects (e.g. cost per parcel for the users) and environmental effects (e.g. emissions per parcel and distance per parcel) of several scenarios.

Other articles focus specifically on the effect of the introduction of the UCC on its users, which can be monetary and non monetary. Janjevic and Ndiaye (2015) develop a model for assessing the effects of the introduction of a UCC on the cost of deliveries in Brussels-Capital Region (BE). Van den Berg (2015) analyses the potential value creation by the UCCs and differentiates it according to the direct last-mile value and additional network optimisation value. Blom and van Nunen (2009) identifies and quantifies the value of Binnestadservice UCC in Nijmengen (NL) for its customers. Roca-Riu and Estrada (2012) provide a model estimating the effects of UCCs on the operational costs and apply it to the case of a UCC in L'Hospitalet de Llobregat in Barcelona (ES).

A novel approach in the evaluation of the city logistics measures is the business model analysis. A business model analysis is an explanation of how an organization does business, describing the value that an organization offers to its customers, and the 
activities, resources and partners required for creating, marketing and delivering this value (Balm et al., 2014). STRAIGHTSOL project (see: (STRAIGHTSOL, 2014a)) applies the business model canvas to assessing the UCC in L'Hospitalet de Llobregat in Barcelona. Björklund and Abrahamsson (2015) analyses business models of three successful city consolidation initiatives in order to identify critical components, similarities and differences between the models applied.

Another approach for city logistics evaluation is the multi-criterion evaluation. Multi-criterion evaluation techniques allow both quantitative and qualitative multi-dimensional effects to be incorporated (Macharis et al., 2009). For example, Gonzalez-Feliu and Salanova (2012) propose a multi-criteria approach to assessing collaborative urban freight transportation systems to help the urban goods movement decision makers in their strategic choices (for both public and private stakeholders). The MultiActor Multi-Criteria Analysis or MAMCA (see : (Macharis, 2007; Macharis et al., 2009)) allow integrating multiple stakeholder views and has already been applied to a series of city logistics initiatives, including Urban Consolidation Centres. STRAIGHTSOL project (see: (STRAIGHTSOL, 2014b)) applies the Multi-Actor MultiCriteria Analysis to assessing the UCC in L'Hospitalet de Llobregat in Barcelona (ES). Lebeau et al. (2015b) apply the Multi-Actor MultiCriteria Analysis for assessing several scenarios of implementation of UCCs servicing the BrusselsCapital Region (BE).

Finally, another emerging evaluation technique for the UCC evaluations is the multi-agent based evaluation. Multi-agent system provides potential to meticulously replicate the urban freight movement by mapping complexity of domain, time and discipline simultaneously and describing the domain naturally and flexibly (Anand et al., 2010). Two papers apply agent-based modelling to assess the introduction of the UCCs. van Duin et al. (2012) develop an agentbased model in order to assess the dynamic behaviour between stakeholders linked to the introduction of a UCC. Wangapisit et al. (2014) apply a multi-agent model for studying the effect of city logistics measures consisting of the joint delivery systems, an urban distribution centre, and parking space restriction.

The literature review performed in this section shows that there are in fact numerous approaches to UCC evaluation. However, it is to be noted that despite the recommendations made by several authors, no supply-chain specific approach has been applied yet to the assessment of these city logistics initiatives.

\section{Presentation of the SCOR model}

The Supply Chain Operations Reference (SCOR) was developed by the Supply Chain Council in 1996 with the objective to conceive a framework to evaluate and compare supply chain activities and performance (Supply Chain Council, 2012) and is now widely used both in research and industrial sectors (Bolstorff, 2007). The basic purpose of this framework is to define a standard supply chain model for any industry, helping to structure the whole process and to highlight key aspects specific for each organisation. The SCOR process reference model contains four major elements (Supply Chain Council, 2012; Huan et al., 2004): (1) Processes (i.e. description of processes and framework of relationships between the processes); (2) Performance metrics (i.e. metrics to measure process performance); (3) Best practices (i.e. practices that produce best-in-class performance) and (4) People (i.e. training and skills requirements). In this article, we will focus on the two first elements of the SCOR model.

The description of processes in SCOR is made according to a four-level structure (see Figure 2). Process types are decomposed into process categories. They are decomposed into process elements and finally into industry specific activities (Huan et al., 2004). The last version of the SCOR model $\left(11^{\text {th }}\right.$ version), published by Supply Chain Council describes the supply chain at the first level, with the following processes for each organisation: Plan, Source, Make, Deliver, Return and Enable (see Figure 1). 


\begin{tabular}{|c|c|c|c|c|}
\hline & \multicolumn{2}{|c|}{ Level } & \multirow[t]{2}{*}{ Examples } & \multirow[t]{2}{*}{ Comments } \\
\hline & $\#$ & Description & & \\
\hline \multirow{3}{*}{$\begin{array}{l}\text { Within } \\
\text { scope } \\
\text { of } \\
\text { SCOR }\end{array}$} & 1 & $\begin{array}{l}\text { Process Types } \\
\text { (Scope) }\end{array}$ & $\begin{array}{l}\text { Plan, Source, Make, Deliver, } \\
\text { Return and Enable }\end{array}$ & $\begin{array}{l}\text { Level-1 defines scope and content } \\
\text { of a supply chain. At level- } 1 \text { the } \\
\text { basis-of-competition performance } \\
\text { targets for a supply chain are set. }\end{array}$ \\
\hline & 2 & $\begin{array}{l}\text { Process Categories } \\
\text { (Configuration) }\end{array}$ & $\begin{array}{l}\text { Make-to-Stock, Make-to- } \\
\text { Order, Engineer-to-Order } \\
\text { Defective Products, MRO } \\
\text { Products, Excess Products }\end{array}$ & $\begin{array}{l}\text { Level-2 defines the operations } \\
\text { strategy. At level-2 the process } \\
\text { capabilities for a supply chain are } \\
\text { set. (Make-to-Stock, Make-to-Order) }\end{array}$ \\
\hline & 3 & $\begin{array}{l}\text { Process Elements } \\
\text { (Steps) }\end{array}$ & $\begin{array}{l}\text { - Schedule Deliveries } \\
\text { - Receive Product } \\
\text { - Verify Product } \\
\text { - Transfer Product } \\
\text { - Authorize Payment }\end{array}$ & $\begin{array}{l}\text { Level-3 defines the configuration of } \\
\text { individual processes. At level-3 the } \\
\text { ability to execute is set. At level-3 } \\
\text { the focus is on the right: } \\
\text { - Processes } \\
\text { - Inputs and Outputs } \\
\text { - Process performance } \\
\text { - Practices } \\
\text { - Technology capabilities } \\
\text { - Skills of staff }\end{array}$ \\
\hline $\begin{array}{l}\text { Not in } \\
\text { scope }\end{array}$ & 4 & $\begin{array}{l}\text { Activities } \\
\text { (Implementation) }\end{array}$ & $\begin{array}{l}\text { Industry-, company-, location- } \\
\text { and/or technology specific } \\
\text { steps }\end{array}$ & $\begin{array}{l}\text { Level-4 describes the activities } \\
\text { performed within the supply chain. } \\
\text { Companies implement industry-, } \\
\text { company-, and/or location-specific } \\
\text { processes and practices to achieve } \\
\text { required performance }\end{array}$ \\
\hline
\end{tabular}

Figure 1:SCOR as a hierarchical process model (Supply Chain Council, 2012)

SCOR also provides generic performance metrics. The Supply Chain Council supposes it is impossible to effectively manage the supply chain if every supply chain partner uses different metrics (Supply Chain Council, 2012). Alignment of the metrics throughout the organization and with the goal is mandatory for performance of the overall organization. Performance indicators/metrics proposed by the SCOR model are divided into 5 categories of performance attributes: (1) Reliability (i.e., the degree to which tasks are performed as expected), (2) Responsiveness (i.e. speed at which tasks are fulfilled), (3) Agility (i.e. an indication of the capability of a supply chain to answer to change and external influences), (4) Costs (i.e. how much is spend throughout the supply chain) and (5) Assets (i.e. how efficiently the organization is using its assets) (Supply Chain Council, 2012). A detailed overview of all SCOR metrics of the version 11.0 can be found in (Supply Chain Council, 2012). Finally, SCOR proposes proposing a set of strategic environmental metrics (referred to as "Green SCOR") that can be added to the SCOR Model to effectively allow the SCOR Model to be used as a framework for environmental accounting (Supply Chain Council, 2012).

\section{Relevance of the SCOR model for assessing Urban Consolidation Centres projects}

The different evaluation approaches described in the literature review in the section 0 correspond to specific views on the UCC implementation. We can see that most of the studies focus on the evaluation of the UCCs at a firm level (e.g. UCC financial viability) and the city level (e.g. environmental impact) or some combination of the two previous approaches. In fact, very few approached consider UCCs in a wider supply chain context.

Several authors already highlighted this issue. Browne et al. (2005) conclude that the wider supply chain implications are generally not explored in detail within the literature identified as no comprehensive investigation of wider supply chain impacts has been found in any of the literature and highlights the need for further investigation into the total supply chain costs and benefits associate with the use of UCCs. Marinov 
et al. (2008) indicate that freight transport and logistics operations in urban areas cannot be viewed and studied in isolation but rather in the context of the entirety of supply chains that typically cross the geographical boundaries of urban areas. Same authors mention the need to raise awareness of the UCC concept, especially of the benefits from cost reductions through the optimisation of other supply chain activities as a result of UCC usage.

It is to be noted that some current approaches do integrate some level of supply chain assessment. For example, the business model canvas analyses the firm activities with regards to its customers and suppliers. In this framework, SCOR model can be used to identify the supply chain impacts for the UCC users before studying how to convert these values into revenues for the UCC in business model canvas. Moreover, SCOR model brings an additional point of view compared to the business model canvas. In fact, the application of the aforementioned evaluation technique brings challenges with regards to the definition of the problem owner or the allocation of the costs and benefits Balm et al. (2014). SCOR model allows overcoming some of these challenges since it privileges the overall impact on the supply chain performance rather than local optimisation. For example, SCOR will to allow quantifying the cost variation for each supply chain actor, but will also allow aggregating this in an overall cost metric. Consequently, when considering a new city logistics scheme (e.g. a UCC), SCOR allows pinpointing the impact on the overall supply chain performance beyond its allocation between actors.

Another distinctive element of business model canvas for city logistics is the value proposition to society (Björklund and Abrahamsson, 2015) - in some cases, the value to society is taken into account as part of the value proposition (Balm et al., 2014). The SCOR allows taking into account explicitly the environmental performance of the supply chain through Green SCOR metrics.

Another evaluation approach that allows integrating supply chain metrics is the MAMCA approach. However, this assessment technique has a larger focus as it includes a comprehensive group of stakeholders who can be internal or external to the supply chain, providing valuable information about the acceptance of the city logistics initiatives. SCOR has a more specific focus on the supply chain performance and its metrics could therefore be used as input for defining indicators for a MAMCA analysis.

Finally, SCOR method presents some additional advantages. SCOR model resulted from the consensus between several industry leaders and is therefore adapted to the supply chain requirement of a broad variety of industries and applications (Supply Chain Council, 2012). It calls upon standard processes and performance indicators which provides the standards needs to communicate and enabling benchmarking (Di Martinelly et al., 2009). This permits to enhance comparability and put the evaluation of city logistics initiatives in a context of the evaluation of best practices across supply chains. Furthermore, the SCOR model is the only supply chain framework that links performance measures, best practices, and software requirements to a detailed business plan model (Klapper et al., 1999).

There are however two main limitations of this model. First, being a 'one size fits all' model, the framework can appear too idealistic. Sometimes reality needs to be fit into the model (Lauras, 2004). Second, (LEPORI, 2012) signals that not all activities can be assigned unequivocally to a process.

With this in mind, we argue that a supply-chain centred approach and the use of the SCOR method that is specifically designed for supply chain purposes cannot replace the existing evaluation techniques but can provide a complementary view and shed a new light on the role of these logistical platforms in a context of a sustainable city distribution.

\section{Identification of UCC operating models}

UCCs projects can vary across different dimensions. Allen et al. (2012) classify them based on the type of operation and geographical area served in the following three categories: (1) UCCs serving all or part of an urban area, (2) UCCs serving large sites with a single landlord and (3) Construction project UCCs. Construction project UCCs are very specific 
with regards to the type of goods handled and can be considered separately, but the first two categories of the UCCs can share some similarities as they can both handle retail goods for example. Moreover, in a case where the use of UCC is not compulsory and the UCC is situated at an off-site location, the sitespecific UCCs are very similar to those serving all or part of an urban area. The UCCs within these two categories can however have significant differences in terms of proposed activities. For this reason, we will propose a classification of the UCCs within the first two categories based on the type of activities that they propose. In order to do this, we will perform a review of $10 \mathrm{UCC}$ implementation cases, identify the activities performed in each UCC and then highlight the resulting operating models.

Selection of the case studies of Urban Consolidation Centres

In order to identify the new UCC operating models authors have analysed 10 recent case studies of Urban Consolidation Centres that were documented in the literature. Error! Reference source not found. presents the summary of the literature review and interviews that were performed.

Table 1: Overview of UCCs case studies

\begin{tabular}{|c|c|}
\hline UCC Name & Documentation \\
\hline $\begin{array}{l}\text { Bristol-Bath consolidation centre } \\
\text { (UK) }\end{array}$ & $\begin{array}{l}\text { (Jones et al., 2008); (TRAILBLAZER, 2010a);(van Duin et al., 2010); (Moore, 2011); } \\
\text { (Rees and Gahan, 2011); (Paddeu et al., 2013); (CIVITAS, 2013) }\end{array}$ \\
\hline Meadowhall UCC, Sheffield (UK) & (Yorkshire and Humber Assembly, 2004); (Jones et al., 2008) \\
\hline $\begin{array}{l}\text { Heathrow retail consolidation centre } \\
\text { (UK) }\end{array}$ & $\begin{array}{l}\text { (OSMOSE, 2007); (Bastien, 2007); (Jones et al., 2008); (TRAILBLAZER, 2010b); } \\
\text { (Transport for London, 2015a); (Rees and Gahan, 2011) }\end{array}$ \\
\hline Lucca consolidation centre (IT) & $\begin{array}{l}\text { (Björklund and Abrahamsson, 2015); (Di Bugno, 2010); (Layman, 2008); } \\
\text { (TRAILBLAZER, 2010c); (Luccaport, 2015) }\end{array}$ \\
\hline Cityporto Padova (IT) & $\begin{array}{l}\text { (Morana and Gonzalez-Feliu, 2010); (BESTFACT, 2013); (Rossi and Giordani, 2011); } \\
\text { (Vaghi, 2014); (Morana, 2014); (Interporto Padova SA, 2015); (Pandolfo, 2015) }\end{array}$ \\
\hline ELCIDIS, La Rochelle (FR) & (ADEME, 2004); (Renaudin, 2014); (Proxiway, 2015) \\
\hline Binnenstadtservice Nijmengen (NL) & $\begin{array}{l}\text { (Van Rooijen and Quak, 2009; (Blom and van Nunen, 2009); (van Duin et al., 2010); } \\
\text { (Björklund and Abrahamsson, 2015) }\end{array}$ \\
\hline City Depot (BE) & (Schepers, 2013); (CityDepot, 2015); (Lovens, 2015) \\
\hline Borlänge consolidation centre (SE) & (TRAILBLAZER, 2010d); (Björklund and Gustafsson, 2012) \\
\hline Camden Consolidation Centre (UK) & (Churchill, 2014); (Transport for London, 2015b); (LaMilo, 2015); (Symonds, 2015) \\
\hline
\end{tabular}

\section{Identification of the UCC activities}

Based on the literature review and interviews, we have identified a series of activities that were performed at the analysed UCCs. In the following section, we will provide an overview of the different services and activities that can be offered by the UCCs. For each service, we will also provide a review of the potential benefits that were documented in the literature.

\section{Consolidation and cross-docking}

The consolidation is the basic service offered by the UCCs. It consists of consolidating multiple daily deliveries from a single or multiple suppliers into a single load to minimize empty-running, transport emissions and costs, while increasing productivity (Triantafyllou et al., 2014).

In theory, consolidation can lead to decreased costs of operations because of increased vehicle utilisation. For example, (Transport for London, 2015a) mentions a 90\% use of vehicle load capacity for the Heathrow airport UCC leading to a $75 \%$ 
reduction in the number of vehicles delivering to the airport. However, consolidation with transhipment does not always lead to desired economies of scale because of the costs involved with the construction and the operation of the transhipments as well as negative effects linked to the necessity of using a single transhipment point (Button and Pearman, 1981; Van Duin et al., 2008). The impact on the transport distance is not clear from the literature. For example, (Transport for London, 2015b) mentions procurement savings from reducedsupply distances for the The London Boroughs Consolidation Centre: and (Transport for London, 2015a) mentions a saving of up to $£ 5,000$ in fuelbills per supplier per annum for the Heathrow UCC whereas (Blom and van Nunen, 2009) mentions that distance savings are not substantial for the Binnenstadservice in Nijmengen.

However, the impact on the driving time seems to be positive. In fact, the cross-docking performed at the UCC allows for deliveries to be made to a UCC at a time to suit suppliers leading to potential reductions in transport costs (Triantafyllou et al., 2014). Therefore, delivery companies experience an increased flexibility over delivery time (with added possibility of overnight deliveries for the next morning), avoiding traffic rush hours, and the option of scheduling vehicles and drivers at times which are traditionally quieter for deliveries (Jones et al., 2008). For example, in Bristol-Bath, the 24 hours operations of the centre has allowed deliveries to be taken at any time of day or night (Jones et al., 2008)(OSMOSE, 2007). In the case of Borlänge UCC set-up by a Swedish municipality (see (Björklund and Gustafsson, 2012)), it was also possible to deliver in early mornings when the traffic is less intense. This increased flexibility of the deliveries for transporters can also to lower cost of transport for shippers/transporters and consequently for receivers, knowing that some delivery companies were charging a premium in order to guarantee deliveries during some specific time periods (Jones et al., 2008).

The cross-docking performed at the UCC also allows for deliveries to be made at a time to suit receivers, leading to potential reductions staff costs (Triantafyllou et al., 2014). For the case of Binnenstadservice, due to the time-window regulations shopkeepers have high personnel cost since a part of the delivery is outside opening hours (Van Duin et al., 2008). In this case, the control over delivery time is found to be as a major benefit for the retailers (Blom and van Nunen, 2009). Another example is one retailer in Meadowhall UCC who was forced to accept 6am deliveries despite not opening the store until 10am - the UCC allowed to receiver the early morning deliveries, store then until $10 \mathrm{am}$ an deliver directly into store (Yorkshire and Humber Assembly, 2004).

The consolidation service also has a direct impact on the reliability of the delivery. (TRAILBLAZER, 2010a) and (Moore, 2011) report 100\% on time delivery for UCC in Bristol. Similar conclusions are made by (Paddeu et al., 2013) who mentions the punctuality of deliveries as one of the advantages for retailers. For example, (Transport for London, 2015a) mentions a 99\% delivery success rate, overall project plan reliability increased by $4 \%$ and the on time delivery performance to the retail outlets of $95 \%$ for Heathrow UCC.

(Morana and Gonzalez-Feliu, 2010) mentions that a UCC in Padova has allowed to reduce of the number of failed deliveries since improves the management of the undelivered commands by reserving a special area of the platform for this purpose and quickly informing the customer and finding a solution to deliver.

The consolidation service also impacts the delivery time for both for the transporter/supplier and the receiver, linked to two factors: the decrease of the number of stops and the decrease of the delivery time. For example, UCC in Bristol achieved $76 \%$ reduction in delivery trips for retailers (Moore, 2011) and in the the retailer satisfaction surveys conducted in relation to the UCC, more than half of retailers surveyed are saving over 20 minutes per delivery tasks (TRAILBLAZER, 2010a)(Moore, 2011). (OSMOSE, 2007) mentions more frequent and scheduled deliveries to the Heathrow Airport terminal buildings, enabling retailers to know more accurately when goods will arrive, within agreed delivery periods, helping a retailer to receive merchandise in a shorter time, something that is greatly appreciated, leading to improved staff planning and productivity (Bastien, 2007)(Transport 
for London, 2015a). Several authors (for example (Paddeu et al., 2013), (OSMOSE, 2007), (Bastien, 2007), (Blom and van Nunen, 2009)) mention time savings for suppliers linked to more efficient delivery operations. For example, Borlänge UCC has allowed to decrease the number of stops by $50-$ $75 \%$ (TRAILBLAZER, 2010d). The reduction of the number of drops and the will also result in less uncertainty with planning for transport operators (Blom and van Nunen, 2009).

With regards to the duration of deliveries, (Churchill, 2014) reports a turnaround time of 5 to 20 minutes for suppliers' vehicles in the London Boroughs Consolidation Centre. This figure is in line with classic delivery duration (see: (Routhier et al., 2001)), however, it is to be noted that this duration corresponds to deliveries to several receivers and that the overall time spent on deliveries is therefore reduced. For Heathrow airport, (Transport for London, 2015a) mentions time savings calculated to be 234 hours per week for Heathrow UCC.

\section{Stockholding and replenishment}

UCCs also present an opportunity for stockholding, inventory monitoring (i.e. information collection and analysis linked to in-store inventory systems (Triantafyllou et al., 2014)) and replenishment (i.e. splitting big and unmanageable deliveries into smaller regular deliveries throughout the day, also called stock buffering (Triantafyllou et al., 2014)). These services are commonly proposed by the recent UCCs. In Binnenstadservice, retailers can purchase extra storage so they can use their shop to store goods or rent storage space elsewhere (Van Rooijen and Quak, 2009). CEDM Lucca allows for thirdparty remote warehousing services, providing space rental, remote stocking services and related electronic services (e.g. stock state information, replenishment order submission, etc.) for interested shops and other service operators (Ambrosino et al., 2007)(Di Bugno, 2010). Heathrow Consolidation Centre offers remote storage and stock room management for inventory at point of use at the terminals (TRAILBLAZER, 2010b). Meadowhall UCC proposes storage facilities with management and collection of surplus stock, single item visibility and ordering on intranet and multiple daily deliveries (Yorkshire and Humber Assembly, 2004).

These services can yield significant benefits for the participating retailers. Stockholding and short-time storage and the application of the JIT-principle and the transhipment facility at the distribution centre allows shopkeepers to reduce their stocks in the shops and increase the sales surface (Van Duin et al., 2008)(Jones et al., 2008). (Jones et al., 2008) demonstrates that in the Meadowhall Centre UCC in Sheffield, UK, clothes retailers have reduced from the typical $30 \%$ of back of house space to roughly $1 \%$. Bristol, more frequent deliveries lead to less space is required in-store to stock products back of house, allowing retailers to maximise profitable selling space (TRAILBLAZER, 2010a). However, the effect will vary strongly between shops since the adjustment of the physical space is not always possible (Van Duin et al., 2008). The service can also be relevant for some exceptional storage needs: in Meadowhall UCC, one retailer undergoing a refit of their store shortened the refurbishment period by two days by removing all shop stock to The UCC to allow more efficient working (Yorkshire and Humber Assembly, 2004).

The additional floor space can also allow increasing the product offer and availability, with many additional items available on the shop floor at any one time (Jones et al., 2008)(Triantafyllou et al., 2014) and an increased security of stock (Bastien, 2007). For example, (Bastien, 2007) reports better product availability through increased delivery frequency and offsite storage at the Heathrow airport. On one hand, this can be relevant for products difficult to store: for example, in Meadowhall, one store did not have enough space to store products and needed daily deliveries to ensure constant availability - the use of the UCC allowed to drop from 7 to one delivery per week with $100 \%$ stock availability and an increase of $5 \%$ on the sales of the product in question (Yorkshire and Humber Assembly, 2004). On the other hand, this can be relevant for the seasonal or peak storage (Triantafyllou et al., 2014): in fact, (Van Duin et al., 2008) shows that it is difficult to stock small volumes for short and long term, preventing shopkeepers to anticipate with an extra buffer for their peak-season demands. 
Replenishment allows to decrease the lead times (Rees and Gahan, 2011), increase response to customer needs and therefore eliminate lost sales (Triantafyllou et al., 2014). For example, retailers at Meadowhall have reported instances in which certain items have not been available within a store, but have been able to retrieve from the UCC in response to customer requests within the time that customers stay at the centre (Jones et al., 2008). (TRAILBLAZER, 2010b) reports support service of emergency or ad-hoc deliveries to the Heatrow airport at short notice.

Finally, Inventory Monitoring can also allow to increase the visibility of the supply chain and lead to better availability and service levels (Triantafyllou et al., 2014). The use of the UCC allows more reliable and accurate inventory management (Rees and Gahan, 2011). Moreover, a number of participating retailers are reporting decreases in shrinkage rates when using UCC schemes (Jones et al., 2008). For example, (Yorkshire and Humber Assembly, 2004) reports that the Meadowhall UCC helped reduced stock shrinkage by $70 \%$ since it offers clear product visibility so that employees know the products are being closely monitored and acts as a strong dissuader for theft. (Moore, 2011) reports no losses and damaged for the Bristol UCC and the security of the deliveries in terms of damages and shortages is also reported as a benefit by (Paddeu et al., 2013).

\section{Gate-keeping operations and pre-retailing}

Gate-keeping Operations consist of screening of delivered and returned products at a UCC and can help alleviate some of the problems associated with the quality of product returns and reduce unnecessary transport (Triantafyllou et al., 2014). In Meadowhall, the UCC proposes the receipt and inspection of product any time (Yorkshire and Humber Assembly, 2004). At the Heathrow airport, the UCC is a central point for receipt of all incoming deliveries and all processing including security scanning (Jones et al., 2008). Moreover, the UCC performs performance monitoring and ensuring compliance for all the suppliers (Bastien, 2007), leading to improved security (TRAILBLAZER, $2010 \mathrm{~b}$ ). If the security question is particularly relevant for airports, we can note that other UCCs such as Meadowhall UCC can offer additional security measures over and above the warehouse security (e.g. sealed cages) (Jones et al., 2008).

UCC schemes can offer a variety of pre-retail options (or pre-merchandizing activities), such as quality/quantity checks, unpacking, sorting, products preparation for display and price labelling, allowing to streamline the process from the UCC to the shop floor (Triantafyllou et al., 2014)(Jones et al., 2008). Pre-retail activities are carried out for example at Meadowhall Shopping Centre UCC in Sheffield (Lewis et al., 2007), and at Bristol Broadmead UCC (Jones et al., 2008). For example, in Meadowhall, the clothing garments for one retailers are prepared for display by steaming and hanging prior to delivery in store (Yorkshire and Humber Assembly, 2004). In addition to freeing space previously used for these activities within the shop, this process offers major savings in both staff time and cost and staff morale, allowing retail staff to concentrate on their core sales duties while reducing timeconsuming pre-retail work (Jones et al., 2008). For example, in Bristol, retail staff are able to spend more of their time on core tasks e.g. selling or helping customers and not on logistics or deliveryrelated tasks (TRAILBLAZER, 2010a). A retailer satisfaction survey reported $45 \%$ indicating that staff are less stressed and have improved morale, and $38 \%$ saying that staff can now spend more time with customers (Jones et al., 2008).

\section{Business-to Customer (B2C) Services}

UCCs can offer a range Business-to Customer (B2C) Services, such home delivery or customer collection of products purchased in town or by mail and online orders (Triantafyllou et al., 2014).

For example, Binnenstadservice offers homedeliveries (for example for large goods, such as fridges and computers) (Van Rooijen and Quak, 2009). ELCIDIS in La Rochelle offers home deliveries for large retailers such as Monoprix, Super U and Carrefour (Renaudin, 2014). CEDM is Lucca also offers home delivery services, for generic users (i.e. citizens living in the service area) or specific user categories (e.g. elderly people, etc.) (Ambrosino et al., 2007), but also deliveries to specific locations such as hotels, park\&buy areas, pick-up points or e-lockers (Layman, 2008)(Di 
Bugno, 2010). The CEDM can also operate as a pick-up point for any goods purchased in the historical centre and bound for outside destinations the purchase process may be originated in the ordinary way (i.e. directly at the selling point) or by any distant selling means (e.g phone order placement, e-commerce purchase, etc.) while the transport service between the selling location and the CEDM is provided by the CEDM fleet of electrical vehicles (TRAILBLAZER, 2010c). This can allow transitioning towards "hands-free shopping" systems (i.e. shoppers do not need to carry their purchases with them, and they can easily combine shopping activities with others such as visiting theatres or restaurants, see: (Stratec and others, 2005)). Customer collect by car points, particularly for retailers of haeavier and bulkier goods can lead to an increased customer dwell time within the shopping area and an increased average spend to the benefit of retailers (Jones et al., 2008). UCCs can also offer kitting for just-in time delivery services. For example, Colizen (Paris, France) works with Nespresso - the UCC holds a local stock of Nespresso capsules and receives customer orders online. The capsules are kitted and delivered by appointment on the same day. The operator also offers additional services such as descaling of coffee machines at customers' homes (Guillaume, 2010).

\section{Supplier management and collaborative sourcing}

UCCs also present opportunities for supplier management and collaborative sourcing. For example, (Bastien, 2007) reports that Heathrow airport consolidation centre performs supplier management for the retailers by agreeing time windows for each retailer, monitoring and reporting the supplier performance to the retailers and ensuring compliance of the suppliers. In other cases, the UCC is served as a basis for both supplier management and collaborative sourcing. On one hand, this can lead to an improved management of the supplier portfolio. For example, in the case of Borlänge UCC set-up by a Swedish municipality (see (Björklund and Gustafsson, 2012) and (TRAILBLAZER, 2010d)), the supplier management and collaborative sourcing has allowed to increase the competition between suppliers (i.e. several small suppliers did not have sufficient logistics services to be included in the tender) and the number of suppliers increased from eight in 1999 to fifteen in 2001 with more than $20 \%$ of the food comes from regional food producers. It is to be noted however that in the following two years, the number of minor suppliers has drastically reduced during the last years, and no clear explanation behind this has been identified (Björklund and Gustafsson, 2012)). On the other hand, collaborative sourcing can lead to supplier discounts. For example, the Camden Consolidation Centre (see: (LaMilo, 2015)) has implemented a collaborative sourcing procedure and has reports supplier discounts of 5 to $7 \%$ (Symonds, 2015) which partially a result of a reduction in a number of suppliers (Transport for London, 2015a). In the Borlänge case however, no supplier discount was observed, despite that the number of delivery points were drastically reduced (Björklund and Gustafsson, 2012)). It is to be noted that so far, there are few documented cases of collaborative sourcing and that most of them relate to public institutions (for example: Värnamo case, Katrineholm case documented in (Björklund and Gustafsson, 2012, p. 201) or Southampton case in the Citylab project, see (CityLab, 2015)), but that CityDepot in Belgium (see: (CityDepot, 2015)) also proposes this service to its private customers.

\section{Return logistics}

UCCs can also serve as hubs for return logistics. In fact, packaging, waste collection and recycling at the UCC consists of using the platform as a storage, trans-shipment and/or treatment facility of waste and recyclables produced by participant retailers (Triantafyllou et al., 2014). Returns Management allows suppliers to use UCCs to consolidate returns into a central stream ideally using the available backload capacity of delivery vehicles (Triantafyllou et al., 2014). All of the analysed UCCs propose this type of sercice. In Broadmead, Bristol, retailers have cardboard and plastic materials collected and recycled (Jones et al., 2008). Heathrow airport UCC also receives outgoing waste and recyclable material from stores (Jones et al., 2008). Binnenstadservice offers collection of the clean waste as a service (Van Rooijen and Quak, 2009). 


\section{Other services}

Specific UCCs also offer some other services. CityDepot in Belgium and Lucca UCC also propose transport brokerage services for their customers (CityDepot, 2015; Luccaport, 2015). For example, Lucca UCC proposes national and international deliveries in collaboration with the major carriers and transport operators (Luccaport, 2015). Finally, some UCCs also propose a series of niche services. For example, Lucca UCC proposes transport and storage services for buyers and retailers of Lucca antique market (Luccaport, 2015). La Rochelle UCC propose the pick-up and the deliveries of the laundry (ADEME, 2004).

\section{Summary of different UCC operating models}

Based on the analysis of the case studies, we have been able to identify main activities performed at each UCC (see Table 2). Although differences exist within each category with regards to the scope or the intensity of the performed activities, we can see that there are roughly three major operating models for the UCC experiences:
(1) UCCs based on retail-activities (Bristol-Bath consolidation centre (UK), Meadowhall UCC (UK) Heathrow retail consolidation centre (UK)): these UCCs are relevant to clearly defined retail areas or retail sites and focus on activities such as temporary storage or pre-retailing, providing a clear added value for participating retailers. The main target are the participating retailers and there is little evidence of proposed B2C services.

(2) Generalist UCCs (Lucca consolidation centre (IT), Cityporto Padova (IT), ELCIDIS, La Rochelle (FR), Binnenstadtservice Nijmengen (NL), City Depot (BE)): these UCCs diversify their activities and propose consolidation, value-added services as well as B2C services, targeting a range of actors such as shippers, carriers, retailers and private customers.

(3) Public stakeholders UCC (Borlänge consolidation centre (SE), Camden Consolidation Centre (UK)): these UCCs focus on cross docking activities with some evidence of short-term storage and propose collaborative sourcing activities for the participating parties.

Table 2: Overview of UCCs case studies and activities from the literature review

\begin{tabular}{|c|c|c|c|c|c|c|}
\hline UCC Name & $\begin{array}{l}\text { Consolidation } \\
\text { and cross- } \\
\text { docking }\end{array}$ & $\begin{array}{l}\text { Stockholding, } \\
\text { inventory } \\
\text { monitoring } \\
\text { and } \\
\text { replenishment }\end{array}$ & $\begin{array}{l}\text { Gate-keeping } \\
\text { operations } \\
\text { and pre- } \\
\text { retailing }\end{array}$ & $\begin{array}{l}\text { Business-to } \\
\text { Customer } \\
\text { (B2C) } \\
\text { Services }\end{array}$ & $\begin{array}{l}\text { Supplier } \\
\text { management } \\
\text { and } \\
\text { collaborative } \\
\text { sourcing }\end{array}$ & $\begin{array}{l}\text { Return } \\
\text { logistics }\end{array}$ \\
\hline $\begin{array}{l}\text { Bristol-Bath } \\
\text { consolidation } \\
\text { centre (UK) }\end{array}$ & ++ & ++ & ++ & - & - & ++ \\
\hline $\begin{array}{l}\text { Meadowhall } \\
\text { UCC, Sheffield } \\
\text { (UK) }\end{array}$ & ++ & ++ & ++ & - & & ++ \\
\hline $\begin{array}{l}\text { Heathrow retail } \\
\text { consolidation } \\
\text { centre }(\mathrm{UK})\end{array}$ & ++ & ++ & ++ & - & - & ++ \\
\hline $\begin{array}{l}\text { Lucca } \\
\text { consolidation } \\
\text { centre (IT) }\end{array}$ & ++ & ++ & - & ++ & & ++ \\
\hline $\begin{array}{l}\text { Cityporto } \\
\text { Padova (IT) }\end{array}$ & ++ & + & - & + & & ++ \\
\hline $\begin{array}{l}\text { ELCIDIS, La } \\
\text { Rochelle (FR) }\end{array}$ & ++ & ++ & - & ++ & & - \\
\hline Binnenstadtservi & ++ & ++ & - & ++ & & ++ \\
\hline
\end{tabular}


ce Nijmengen

(NL)

\begin{tabular}{|c|c|c|c|c|c|c|}
\hline City Depot (BE) & ++ & ++ & - & ++ & + & ++ \\
\hline $\begin{array}{l}\text { Borlänge } \\
\text { consolidation } \\
\text { centre (SE) }\end{array}$ & ++ & + & - & - & ++ & ++ \\
\hline $\begin{array}{l}\text { Camden } \\
\text { Consolidation } \\
\text { Centre (UK) }\end{array}$ & ++ & + & - & - & ++ & ++ \\
\hline
\end{tabular}

\section{Application of SCOR model to different UCC operating models}

The application of the SCOR model to different operating models of UCCs is done in two steps: (1) modelling with SCOR the supply chain processes without the UCC and with the UCCs in order to highlight those that are affected by the introduction of this new service; (2) identification of the performance metrics relevant to the identified processes and aggregation of the metrics according to their category.

In order to model the supply chain operations, we have first identified all the supply chain actors. Other than the UCC, actors will depend on the considered operating models and can be put in two major categories: transporters (who can be a third party transporters or shippers for all types of operating models) and receivers (who can be retailers for retail-based or generalist UCCs, private customers for generalist UCCs performing B2C services or actors such as a municipalities for public UCCs). The next step is the identification of the relevant processes and sub-processes (in the case of UCC operations, the sub-processes will always be part of the plan, source, deliver, return and enable processes). The modelling of the processes allows highlighting which activities are performed by each actor and how these activities change with the introduction of the UCC. An example of the modelling of the SCOR processes for the retailbased UCC can be seen on the following pages. Figure 3 shows the processes without the UCC and Figure 4 shows the processes with the UCC. We can see that the introduction of the UCC results in the shifting of certain activities from the retailer towards the UCC (e.g. the verification of the products and the management of the returns), allowing the retailer to focus more on the core activities. We can also see the appearance of some new activities such as sE3 Manage Data and Information. However, the graphical representation of the processes at Figure 3 and Figure 4does not allow to fully appreciate certain elements such as the reduction of the lead time for restocking orders by the retailers. These elements will be accounted for in the second phase of the application of the SCOR model, the identification of performance metrics.

The generalists UCCs will have a similar process description for the retail deliveries as well as a parallel branch for the $\mathrm{B} 2 \mathrm{C}$ services such as the home deliveries. The public UCCs will not include the pre-retail activities but will have a much higher focus on the supplier management and sourcing.

Once that the SCOR processes have been modelled it is possible to identify the performance metrics relevant to all sub-processes. The Table 3 shows the performance metrics according to different categories for the three operating models as well as for a simple transhipment centre where only crossdocking and consolidation activities are performed. For each of the performance metrics, the relevant stakeholders are identified. We can draw several conclusions. First of all, UCCs can in fact yield significant supply chain benefits and positively influence its performance beyond elements that are traditionally considered in their evaluations such as the capacity utilisation (Asset Utilisation) and the environmental impact (Green SCOR). In fact, UCCs can significantly improve the supply chain 
performance with regards to its reliability, responsiveness and agility. These impacts (e.g. delivery reliability, reduction of the lead time, stock availability) have been documents in the literature review of the $10 \mathrm{UCC}$ case studies performed in the previous section and the application of the SCOR model has allowed to identify the related performance metrics which can be measured (e.g. for the delivery reliability: RL.3.32 Customer Commit Date Achievement Time Customer Receiving, RL.3.33 Delivery Item Accuracy, RL.3.34 Delivery Location Accuracy and RL.3.35 Delivery Quantity Accuracy). Secondly, we can see that the new operating UCC models described in this paper have indeed a much higher impact on the overall supply chain performance than a simple transhipment centre, confirming the conclusion that the value-added services performed at the UCC can indeed increase their attractiveness. Finally, we can see some differences in terms of impact between the different operating models: for example, the metrics RL.3.36 Fill Rate will only be relevant to B2C services for generalists UCCs whereas the metrics RS.3.3 Assess Supplier Performance Cycle Time will only be relevant for retail and public UCCs 


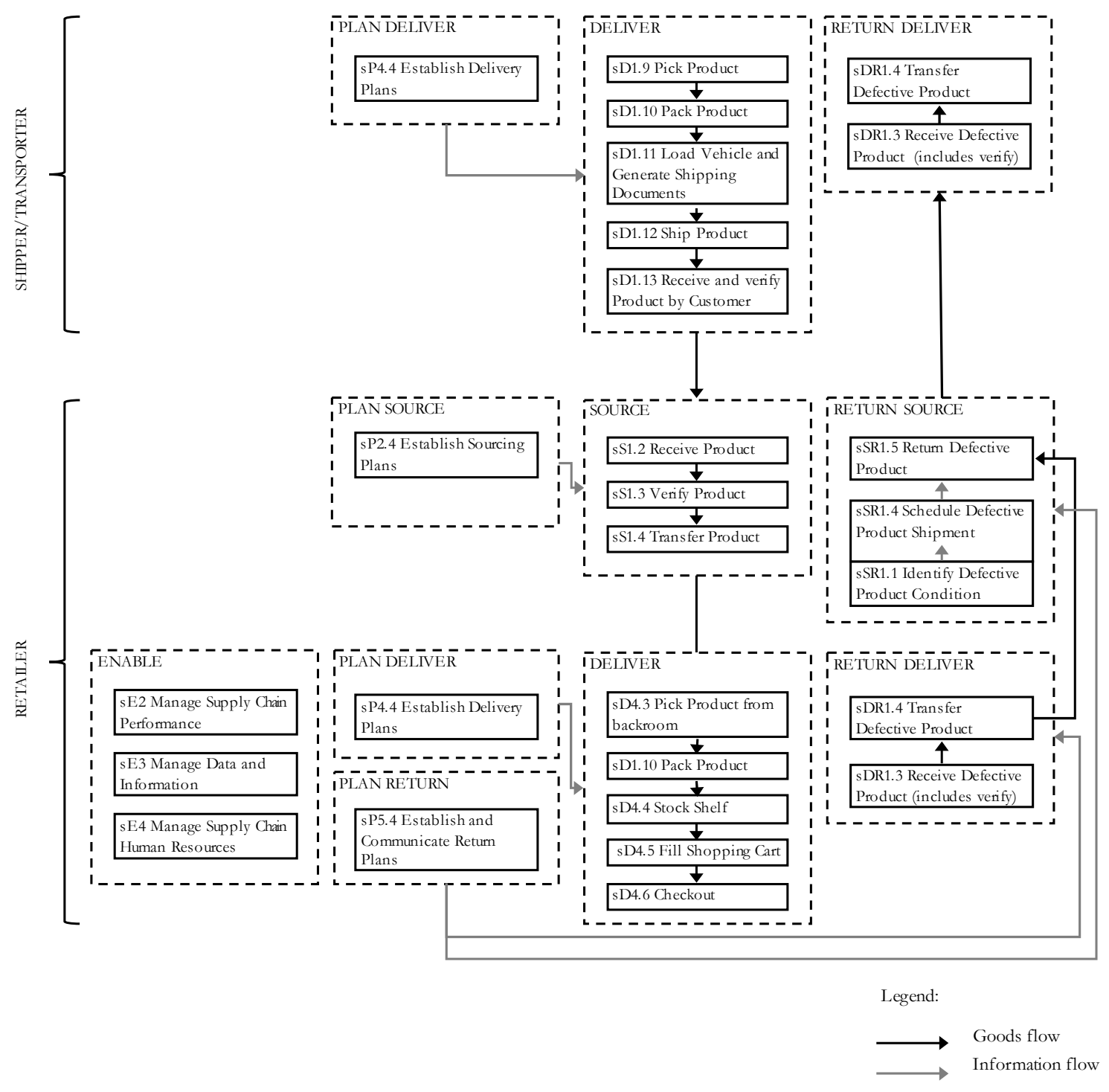

Figure 2: Modelling of the SCOR processes without the Urban Consolidation Centre for Retail-Based UCC 
Janjevic, M et al/ Applying the Supply Chain Operations Reference (SCOR).....

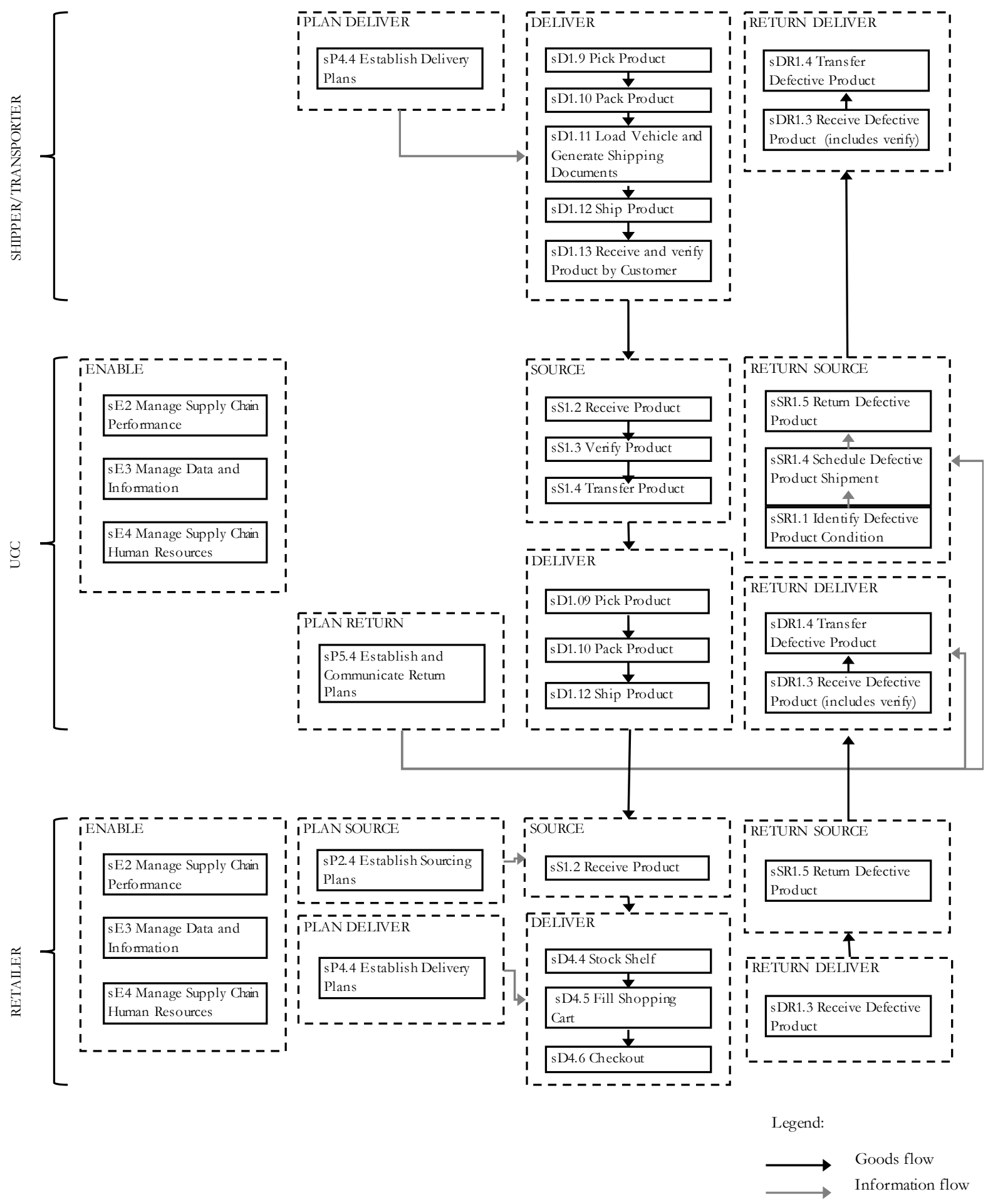

Figure 3: Modelling of the SCOR processes with the Urban Consolidation Centre for Retail-based UCC 
Table 3: Performance metrics for various operating models $(R=$ receiver, $T=$ transporter/shipper, $C=$ private customer, $(++)=$ major impact, $(+)=$ minor impact $)$

\begin{tabular}{|c|c|c|c|c|}
\hline Indicator & Transhipment & Retail UCC & Generalist UCC & Public UCC \\
\hline 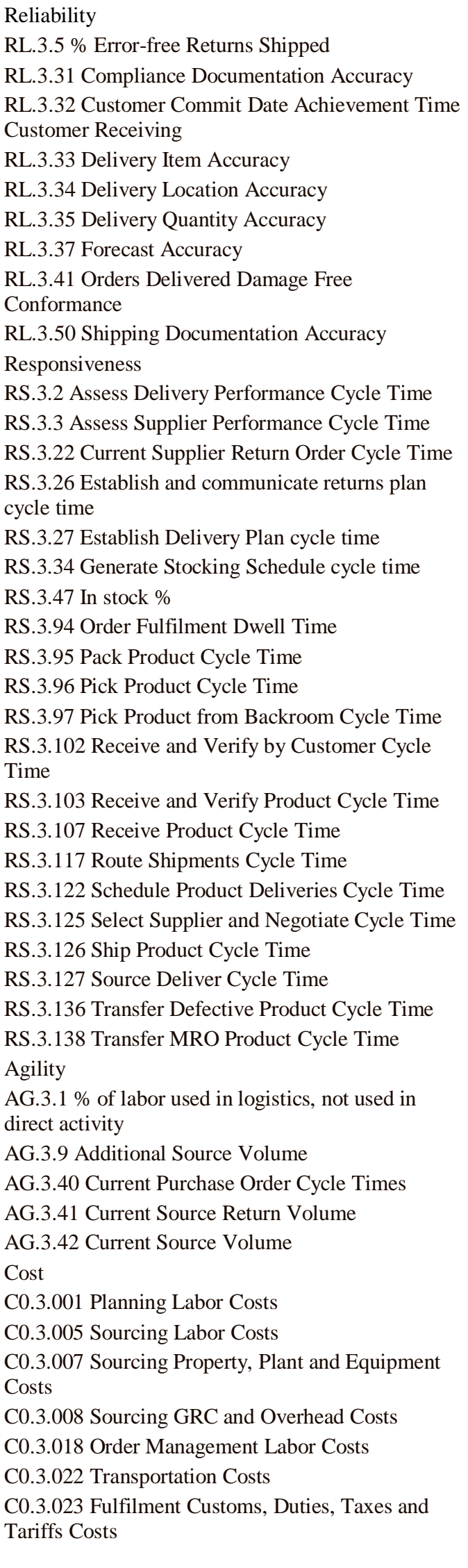 & $\begin{array}{l}\mathrm{T}(++) \\
\mathrm{T}(++) \\
\mathrm{T}(++) \\
\mathrm{T}(++) \\
\mathrm{T}(++) \\
\mathrm{T}(++)\end{array}$ & 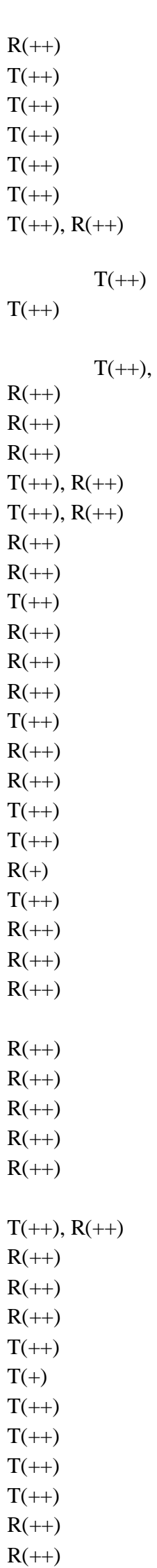 & 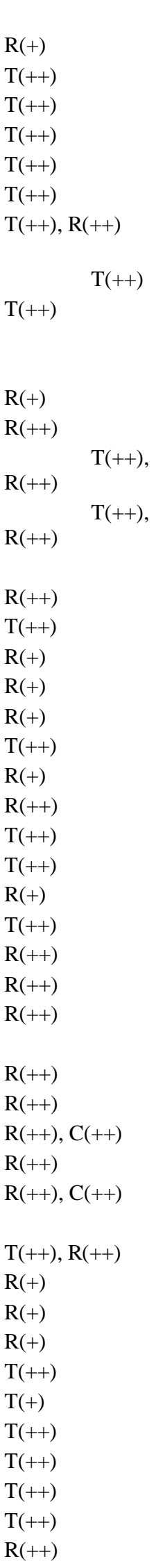 & $\begin{array}{l}\mathrm{T}(++) \\
\mathrm{R}(+) \\
\mathrm{R}(++) \\
\mathrm{T}(++) \\
\mathrm{T}(++) \\
\mathrm{R}(++) \\
\mathrm{T}(++) \\
\mathrm{R}(++) \\
\mathrm{R}(++) \\
\mathrm{R}(++) \\
\mathrm{R}(++) \\
\mathrm{R}(++) \\
\mathrm{R}(++) \\
\mathrm{R}(++) \\
\mathrm{R}(++) \\
\mathrm{T}(++), \mathrm{R}(++) \\
\mathrm{R}(+) \\
\mathrm{R}(+) \\
\mathrm{R}(+) \\
\mathrm{T}(++) \\
\mathrm{T}(++) \\
\mathrm{T}(++) \\
\mathrm{T}(++) \\
\mathrm{T}(++) \\
\mathrm{T}(++)\end{array}$ \\
\hline
\end{tabular}




\begin{tabular}{|c|c|c|c|c|}
\hline $\begin{array}{l}\text { C0.3.024 Fulfilment Labour Costs } \\
\text { C0.3.026 Fulfilment Property, Plant and Equipment } \\
\text { Costs } \\
\text { C0.3.027 Fulfilment GRC and Overhead Costs } \\
\text { C0.3.029 Disposition Costs } \\
\text { C0.3.030 Returns GRC and Overhead Costs } \\
\text { Assets } \\
\text { AM.3.8 Average age of Excess Inventory } \\
\text { AM.3.9 Capacity Utilization } \\
\text { AM.3.11 Deliver Fixed Asset Value } \\
\text { AM.3.24 Return Fixed Asset Value } \\
\text { AM.3.37 Percentage Excess Inventory } \\
\text { AM.3.22 Recyclable waste as \% of total waste } \\
\text { AM.3.26 Return Rate } \\
\text { AM.3.28 Percentage Defective Inventory } \\
\text { Green SCOR } \\
\text { GS.3.007 Material Acquisition Management Carbon } \\
\text { Emissions } \\
\text { GS.3.010 Sales Order Management Carbon } \\
\text { Emissions } \\
\text { GS.3.013 Deliver Return Carbon Emissions } \\
\text { GS.3.015 Source Air Emissions } \\
\text { GS.3.017 Deliver Air Emissions } \\
\text { GS.3.018 Return Air Emissions } \\
\text { GS.3.030 Source \% Recycled } \\
\text { GS.3.032 Deliver \% Recycled } \\
\text { GS.3.033 Return \% Recycled }\end{array}$ & $\begin{array}{l} \\
\mathrm{R}(++) \\
\mathrm{T}(++) \\
\mathrm{R}(++) \\
\mathrm{T}(++)\end{array}$ & $\begin{array}{l}\mathrm{R}(++) \\
\mathrm{T}(+) \\
\mathrm{T}(+) \\
\mathrm{T}(++) \\
\mathrm{R}(++) \\
\mathrm{R}(+) \\
\mathrm{R}(+) \\
\mathrm{R}(+) \\
\mathrm{R}(++) \\
\mathrm{T}(++) \\
\mathrm{T}(++) \\
\mathrm{R}(++) \\
\mathrm{T}(++) \\
\mathrm{R}(++) \\
\mathrm{R}(+) \\
\mathrm{T}(+) \\
\mathrm{R}(+)\end{array}$ & $\begin{array}{l}\mathrm{R}(++) \\
\mathrm{R}(+) \\
\mathrm{T}(+) \\
\mathrm{T}(+) \\
\mathrm{T}(++) \\
\mathrm{R}(+) \\
\mathrm{R}(+) \\
\mathrm{R}(+) \\
\mathrm{R}(+) \\
\mathrm{R}(++) \\
\mathrm{T}(++) \\
\mathrm{T}(++) \\
\mathrm{R}(++) \\
\mathrm{T}(++) \\
\mathrm{R}(++) \\
\mathrm{R}(+) \\
\mathrm{T}(+) \\
\mathrm{R}(+)\end{array}$ & $\begin{array}{l}\mathrm{R}(++) \\
\mathrm{R}(++) \\
\mathrm{R}(+) \\
\mathrm{T}(++) \\
\mathrm{T}(++) \\
\mathrm{T}(++) \\
\mathrm{R}(+) \\
\mathrm{R}(+) \\
\mathrm{R}(+) \\
\mathrm{R}(+) \\
\mathrm{R}(++) \\
\mathrm{T}(++) \\
\mathrm{T}(++) \\
\mathrm{R}(++) \\
\mathrm{T}(++) \\
\mathrm{R}(++) \\
\mathrm{R}(+) \\
\mathrm{T}(+) \\
\mathrm{R}(+)\end{array}$ \\
\hline
\end{tabular}




\section{Conclusion}

The present paper proposes the application of the SCOR model in order to investigate the impact on the supply chain performance of several UCC operating models. This allows highlighting that the overall impact on the supply chain performance tends to increase with the number of value-added activities performed at the UCC. In particular, SCOR model allows emphasizing the impact of the UCCs on the reliability, responsiveness and agility of the supply chains. This brings an innovative aspect to the UCC projects evaluation. In fact, many current evaluation methods focus only on cost, environmental or asset utilisation related metrics.

The present approach does however have some limitations. SCOR does not include all activities performed by the supply chain actors. An example of such unaccounted for activity is sales: the UCC impacts on these activities are missing although evidence from literature does tend to suggest that the introduction of the UCCs can in fact increase sales. SCOR model does however allow pinpointing one of the root causes of the sales increase, which is the increased product availability, but does not account for other elements such as the increase in product range resulting from the decreased inventory requirements. In fact, an increase in product range falls within strategic company decisions with regards to its commercial approach. SCOR model does not allow modelling these decisions but does however provide as assessment of the supply chain that aims in evaluating the operational feasibility of the aforementioned decisions.

The next step is to apply this model in practice and to quantify these metrics. The SCOR model presents the advantage of proposing a set of measurable metrics for investigating the supply chain performance and linking them to the operational processes. However, in order to highlight the overall impact of the different UCC operating models on the supply chain performance, it is necessary to provide a weighting and an aggregation of these metrics. This analysis can serve to demonstrate the role of UCCs in sustainable city distribution but also in sustainable supply chain management.

\section{References}

ADEME, 2004. Analyse comparative des systèmes logistiques rochelais et monégasques.

Allen, J., Browne, M., Woodburn, A., Leonardi, J., 2012. The Role of Urban Consolidation Centres in Sustainable Freight Transport. Transport Reviews 32, 473-490. doi:10.1080/01441647.2012.688074

Ambrosino, G., Boero, M., Di Bugno, M., Guerra, S., Librato, A., 2007. A centre for eco friendly city freight distribution: Urban logistics innovation in a mid-size historical city in Italy. ICL 2007.

Anand, N., van Duin, R., Tavasszy, L., 2010. Multi agent modeling for city logistics policy analysis: potentials and challenges, in: Proceedings of the 45th Conference. Presented at the Canadian Transportation Research Forum, IslandBlue Printorium Bookworks, Victoria, BC, Canada, pp. 582-596.

Balm, S., Browne, M., Leonardi, J., Quak, H., 2014. Developing an evaluation framework for innovative urban and interurban freight transport solutions. Procedia-Social and Behavioral Sciences 125, 386397.

Bastien, O., 2007. An Introduction to Retail Consolidation Centres.

BESTFACT, 2013. CITYPORTO - Last mile deliveries in Padua.

Björklund, M., Abrahamsson, M., 2015. Critical components, similarities and differences in business models for urban consolidation. Presented at the Urban freight and behaviour change, Rome.

Björklund, M., Gustafsson, S., 2012. The role of Swedish municipalities in the establishment of urban consolidation centres. Presented at the 18th conference of the Greening of Industry Network.

Blom, F.M., van Nunen, I.J., 2009. Determining the value of Binnenstadservice. nl for their customers. Erasmus Universiteit.

Bolstorff, P., 2007. Supply chain excellence: a handbook for dramatic improvement using the SCOR model. AMACOM Div American Mgmt Assn.

Browne, M., Allen, J., Leonardi, J., 2011. Evaluating the use of an urban consolidation centre and electric vehicles in central London. IATSS Research 35, 1-6. doi:10.1016/j.iatssr.2011.06.002

Browne, M., Sweet, M., Woodburn, A., Allen, J., 2005. Urban freight consolidation centres final report

Button, K.J., Pearman, A.D., 1981. The economics of urban freight transport. Macmillan.

Churchill, K., 2014. A Public Sector Perspective on Consolidation- London Boroughs Consolidation Centre. 
CityDepot, 2015. The expert in smart urban distribution.

CityLab, 2015. Implementations.

CIVITAS, 2013. Freight consolidation in Bath.

Danielis, R., Valeri, E., Rotaris, L., 2015. Performance evaluation methods for Urban freight distribution chains: a survey of the literature. Presented at the Urban freight and behaviour change, Rome.

Di Bugno, M., 2010. Centre for Eco-Friendly City Freight Distribution: Urban Logistics Innovation in Lucca.

Di Martinelly, C., Riane, F., Guinet, A., 2009. A Porter-SCOR modelling approach for the hospital supply chain. International Journal of Logistics Systems and Management 5, 436-456.

Gonzalez-Feliu, J., Salanova, J.-M., 2012. Defining and evaluating collaborative urban freight transportation systems. Procedia-Social and Behavioral Sciences 39, 172-183.

Guillaume, J.-P., 2010. NESPRESSO: Une Supply Chain sous haute pression. Supply Chain Magazine.

Huan, S.H., Sheoran, S.K., Wang, G., 2004. A review and analysis of supply chain operations reference (SCOR) model. Supply Chain Management: An International Journal 9, 23-29.

Interporto Padova SA, 2015. Cityporto.

Janjevic, M., Ndiaye, A., 2015. Modelling the carriers' response to the introduction of urban freight consolidation centres. Presented at the Urban freight and behaviour change.

Janjevic, M., Ndiaye, A.B., 2016. Investigation of the Financial Viability of Urban Consolidation Centre Projects and Application to Brussels-Capital Region. Presented at the WCTR 2016.

Jones, R., Outterside, J., WSP Development and Transportation (Firm), 2008. Freight consolidation and remote storage. WSP Development and Transportation, Salford.

Klapper, L.S., Hamblin, N., Hutchison, L., Novak, L., Vivar, J., 1999. Supply chain management: a recommended performance measurement scorecard. DTIC Document.

LaMilo, 2015. Camden Consolidation Centre Business Case.

Lauras, M., 2004. Méthodes de diagnostic et d'évaluation de performance pour la gestion de chaînes logistiques: application à la coopération maison-mère-filiales internationales dans un groupe pharmaceutique et cosmétique.

Layman, 2008. The Reality of City Logistics in Lucca: the Life CEDM Model.
Lebeau, P., Macharis, C., Janjevic, M., Van Mierlo, J., 2015a. Investigating support for Urban Consolidation Center in Brussels.

Lebeau, P., Macharis, C., Van Mierlo, J., Janjevic, M., 2015b. Implementing an urban consolidation centre: involving stakeholders in a bottom-up approach. Presented at the Urban freight and behaviour.

Leonardi, J., Dablanc, L., van Egmond, P., Guerlain, C., 2015. Feasibility study of a network of consolidation centres in Luxembourg, in: Proceedings of the 9th International Conference on City Logistics.

LEPORI, E., 2012. Apports et limites du modèle SCOR pour l'évaluation de la performance en Supply Chain Management: Application à un entrepôt logistique. INSA de Strasbourg.

Lewis, A., Lagrange, A., Patterson, D., Gallop, N., 2007. South London Freight Consolidation Centre Feasibility Study - Final Report.

Lovens, P., 2015. City Depot - Smart Urban Distribution.

Luccaport, 2015. Luccaport Services.

Macharis, C., 2007. Multi-criteria analysis as a tool to include stakeholders in project evaluation: the MAMCA method. Transport Project Evaluation. Extending the Social Cost-Benefit Approach 115131.

Macharis, C., De Witte, A., Ampe, J., 2009. The multi-actor, multi-criteria analysis methodology (MAMCA) for the evaluation of transport projects: Theory and practice. Journal of Advanced transportation 43, 183-202.

Marcucci, E., Danielis, R., 2008. The potential demand for a urban freight consolidation centre. Transportation 35, 269-284.

Marinov, M., Zunder, T., Islam, D.M.Z., 2008. Urban freight consolidation concepts: is there something missing? Transport Problems 5, 5-12.

Moore, R., 2011. DHL Supply Chain (Fashion) Consolidation Operations.

Morana, J., 2014. Sustainable supply chain management in urban logistics, in: Sustainable Urban Logistics: Concepts, Methods and Information Systems. Springer, pp. 21-35.

Morana, J., Gonzalez-Feliu, J., 2010. Sustainable supply chain management in city logistics solutions: an experience's comeback from Cityporto Padua (Italy).

Morana, J., Gonzalez-Feliu, J., Semet, F., 2014. Urban Consolidation and Logistics Pooling, in: Sustainable Urban Logistics: Concepts, Methods and Information Systems. Springer, pp. 187-210.

OSMOSE, 2007. Heathrow Airport Consolidation Centre (London, UK). 
Paddeu, D., Ricci, M., Fancello, G., Fadda, P., Parkhurst, G., 2013. The Bristol-Bath Freight Consolidation Centre.

Pandolfo, P., 2015. Interview about Cityporto Padova.

Panero, M.A., Shin, H.-S., Lopez, D.P., 2011. Urban Distribution Centers - a Means to Reducing Freight Vehicles Miles Travelled.

Proxiway, 2015. Elcidis, mode d'emploi.

Quak, H., Tavasszy, L., 2011. Customized solutions for sustainable city logistics: The viability of urban freight consolidation centres, in: Transitions towards Sustainable Mobility. Springer, pp. 213-233.

Rees, C., Gahan, N., 2011. CIVITAS in Bath - Urban Freight Consolidation.

Renaudin, M., 2014. Interview on ELCIDIS Logistics Platform.

Roca-Riu, M., Estrada, M., 2012. An Evaluation of Urban Consolidation Centers Through Logistics Systems Analysis in Circumstances Where Companies have Equal Market Shares. Procedia Social and Behavioral Sciences, Seventh International Conference on City Logistics which was held on June 7- 9,2011, Mallorca, Spain 39, 796-806. doi:10.1016/j.sbspro.2012.03.148

Rossi, I., Giordani, S., 2011. Cityporto Padova Conferenza stampa.

Routhier, J.-L., Segalou, E., Durand, S., 2001. Mesurer l'impact du transport de marchandises en ville: le modèle de simulation FRETURB (V.1). Programme national marchandises en ville.

Schepers, M., 2013. Smart Urban Distribution in Hasselt - CityDepot.

STRAIGHTSOL, 2014a. Business models for innovative and sustainable urban-interurban transport.

STRAIGHTSOL, 2014b. Final evaluation of all STRAIGHTSOL city distribution concepts by use of the MAMCA.

Stratec, S.A., others, 2005. City Freight. Inter-and Intra-city Freight Distribution Networks. City Freight Project, European Commission Fifth Framework Programme.

Supply Chain Council, 2012. Supply Chain Operations Reference Model - Revision 11.0.

Symonds, N., 2015. An Urban Freight Solution for the London Borough of Camden and its Partner Boroughs.

Thompson, R.G., 2014. Evaluating City Logistics Schemes. City Logistics: Mapping The Future 101.

TRAILBLAZER, 2010a. Bristol, UK - Consolidation of deliveries to Bristol city centre.
TRAILBLAZER, 2010b. Heathrow Consolidation Centre, UK Consolidation of deliveries to London Heathrow airport.

TRAILBLAZER, 2010c. Lucca, Italy: A centre for Eco-Friendly City Freight Distribution - Urban Logistics Innovation in a Mid-size Historical City in Italy.

TRAILBLAZER, 2010d. Borlänge, Sweden: Consolidation of deliveries to four Swedish municipalities.

Transport for London, 2015a. Case study: Expansion of Consolidation at Heathrow.

Transport for London, 2015b. The London Boroughs Consolidation Centre - a freight consolidation success story.

Triantafyllou, M.K., Cherrett, T.J., Browne, M., 2014. Urban Freight Consolidation Centers. A Case Study in the UK Retail Sector., in: Transportation Research Board 93rd Annual Meeting.

Tsamboulas, D.A., Kapros, S., 2003. Freight village evaluation under uncertainty with public and private financing. Transport Policy 10, 141-156.

Vaghi, C., 2014. MERCI IN CENTRO COMO \& BRESCIA ECOLOGIS: SUCCESSFUL BEST PRACTICE TRANSFERS FROM CITYPORTO PADOVA.

Van den Berg, S.G., 2015. The created value of an Urban Consolidation Centre differentiated in lastmile and network-associated value. TU Delft, Delft University of Technology.

van Duin, J.H.R., Quak, H., Muñuzuri, J., 2010. New challenges for urban consolidation centres: A case study in The Hague. Procedia - Social and Behavioral Sciences 2, 6177-6188. doi:10.1016/j.sbspro.2010.04.029

van Duin, J.H.R., van Kolck, A., Anand, N., Tavasszy, L. órán. A., Taniguchi, E., 2012. Towards an Agent-Based Modelling Approach for the Evaluation of Dynamic Usage of Urban Distribution Centres. Procedia - Social and Behavioral Sciences 39, 333-348. doi:10.1016/j.sbspro.2012.03.112

Van Duin, R., 2009. To be or not to be, a typical City Distribution Centre question. Research on success and failures in ten European CDC-cases. Bijdragen vervoerslogistieke werkdagen 123-145.

Van Duin, R., Quak, H., Munuzuri, J., 2008. Revival of cost benefit analysis for evaluating the city distribution centre concept? Innovations in city logistics, Nova Science, New York 97-114.

Van Rooijen, T., Quak, H., 2010. Local impacts of a new urban consolidation centre-the case of Binnenstadservice. nl. Procedia-Social and Behavioral Sciences 2, 5967-5979. 
Van Rooijen, T., Quak, H., 2009. Binnenstadservice. nl-A New Type of Urban Consolidation Centre. European Transport and Contribution.

Verlinde, S., 2015. Promising but challenging urban freight transport solutions: freight flow consolidation and off-hour deliveries. Universiteit Gent.

Verlinde, S., Macharis, C., Witlox, F., 2012. How to consolidate urban flows of goods without setting up an urban consolidation centre? Procedia-Social and Behavioral Sciences 39, 687-701.
Ville, S., Gonzalez-Feliu, J., Dablanc, L., 2012. The limits of public policy intervention in urban logistics: Lessons from Vicenza (Italy). European Planning Studies 1-14.

Wangapisit, O., Taniguchi, E., Teo, J.S., Qureshi, A.G., 2014. Multi-agent Systems Modelling for Evaluating Joint Delivery Systems. Procedia-Social and Behavioral Sciences 125, 472-483.

Yorkshire and Humber Assembly, 2004. Freight and Logistics Intelligence for the Regional Transport Strategy - A Regional Freight Strategy for Yorkshire and Humber - Baseline Report. 